\title{
Women in Higher Educational Leadership: Representation, Career Progression, and Compensation
}

\author{
Carla Cañas, Caitlyn Keeve, Carmen Ramos, Jocelyn Rivera, \& Michelle L. Samuel \\ Department of Psychology, Mount Saint Mary's University, Los Angeles, CA \\ https://doi.org/10.33697/ajur.2019.026 \\ Students: carlcana6012@msmu.edu,caitkeev@msmu.edu*,carmramo7577@msmu.edu, jocerive5909@msmu.edu \\ Mentor:msamuel@msmu.edu
}

\begin{abstract}
Men in university administration repeatedly outnumber women in leadership positions. The problem under investigation is that this gender gap exists due to barriers to advancement and discrimination in both the hiring process and in the workplace. With less representation of women in higher education leadership, there is a higher risk of bias for women in this field. This study used an ex-post facto methodology and gathered public data from the University of California (UC) Annual Payroll Compensation database. Three separate studies were run to determine the level of gender differences in the representation of educational leaders, compensation, and career progression. Significant differences in gender equity existed, with more men represented at several levels of educational leadership. Significant differences were also found in compensation levels, where men earned more money than women in the same position. Lastly, a small effect, although not significant, was observed when comparing early career gender representation to non-early career gender representation. There are more women recent graduates than men in leadership positions. Together these results suggest that while there are gender gaps in representation and compensation, there may be slow progress towards better representation in early career leadership positions in the UC system. The implication of this research supports further research into factors which impact the compensation of women leaders in academia. Higher education hiring professionals and candidates for leadership positions could benefit from further development of theories around gender equity and representation.
\end{abstract}

\section{KEYWORDS}

Gender Representation; Gender Equity; Higher Educational Leadership; Women; Higher Education; Psychology; Wage Gap; Higher Education Administration

\section{INTRODUCTION}

Today, there are a variety of obstacles that stop women from achieving parity in the workforce. Occupational sex segregation paired with a male dominated work environment are two key barriers that affect women's advancement vertically and horizontally in the corporate arena. ${ }^{1}$ As a result, research has shown that women in fields where they are the minority, demonstrate higher levels of resilience as it relates to their careers including within the field of higher education leadership. ${ }^{2}$ That is, women progress in the field even though they lack representation. This study uses three analyses to further explore this idea. The problems under investigation are how women in higher educational leadership are represented, how this affects compensation, and how they progress in their careers. The method of study is an ex-post facto design that uses the UC Annual Wage database to identify inequities between women and men leaders within the UC System. ${ }^{3}$

While $58.2 \%$ of the United States workforce are women, they are still unequally represented in most fields. ${ }^{3}$ In 2016 , more than $40 \%$ of women in the labor force obtained college degrees. ${ }^{4}$ As of $2017,30 \%$ of university presidents in the United States were women. ${ }^{5}$ Given the national disparity of women's representation in the higher educational leadership, one study sought to see how their university stacked up. Researchers initiated an audit for their large university to assess the representation of women and men in their senior decision-making committees. ${ }^{6} \mathrm{~A}$ base line measurement was taken across committee groups, followed by a proposed initiative to implement parity between men and women leaders on the committee. After one year, the effectiveness of the initiative was measured. The study found some improvements towards gender equity in faculty-based groups however, other groups remained the same. A greater proportion of women were found at the lower academic staff levels and a greater proportion of men were staffed at the higher levels within the faculty of Medicine, Dentistry and Health Science 
school leadership committees. Within this professional staffing sample, the findings indicated greater proportions of women in all categories except at the highest levels.

Just why does this gender representation gap exist? The shortage of women in higher education leadership roles has been problematized in literature, suggesting that women lacked characteristics which led to advancement. ${ }^{7}$ However, some believe that universities are the issue instead. ${ }^{8}$ Higher education scholars in a qualitative study found that the work environments women were in, did not encourage them to become leaders or to build up their careers. Several women discussed that they had to adapt to the "entrenched masculine culture" within a department that was not accommodating to all genders. ${ }^{8}$ Current research shows that men and women do not differ in their desire to advance their careers in higher education administration, but that there are a variety of barriers that prevent women from advancing towards senior leadership. ${ }^{8}$ Factors that affect women's advancement include work relationships, environment, invisible rules, proactivity, and personal circumstances. ${ }^{9}$ These factors show that women face more external than internal hurdles that prevent them from advancing within their careers.

Consequentially, women's advancement to higher positions within universities are hindered despite more women receiving post-secondary degrees. ${ }^{8}$ This suggests that while there are many qualified women to progress into leadership positions, the larger issue is systemic. A 2015 study found that there was a higher proportion of women in lower-level administration when compared to higher levels. ${ }^{6}$ While there are women who rank higher than their male colleagues, the study found that this was not often the case in higher education administration.

To combat this phenomenon the University of California (UC) System has made strides to maintain and increase faculty equity among its ten campuses, such as raising funding to expand and create programs which increase faculty diversity. The UC President delivered a press release stating that $44.1 \%$ of new ladder-rank hires were women and $17.1 \%$ came from minority groups. ${ }^{10}$ These advances are good, but do not eliminate the overall issue of gender and wage disparities. In California, the average salary for women in 2017 was $\$ 45,489$, while the average for men was $\$ 58,225$, which supports the claim for a gender pay gap of $\$ 12,736.92$ between women and men. ${ }^{3}$ In comparison to other states, California ranked \#1 for the narrowest gender wage gap in 2018.11 This may be due to the strength of equal pay laws within the state. New York, a state with a similar infrastructure was also ranked highly in third place, whereas states with weak equal pay laws such as Texas ranked lower in twenty-second place. Because women are amongst all high-ranking positions in academia, including Chancellor, Provost, and Dean in the University of California school system, compensation is an important aspect of their experience to explore.

To investigate how women in higher education leadership roles are represented, how they progress in their career, and how they are compensated, three studies were conducted by the authors. Each study had its own unique hypothesis.

Study 1- Gender Representation in UC Higher Educational Leadership: Is there a significant difference in representation between men and women in higher education leadership roles? It was hypothesized that a significant difference in representation between men and women in higher education leadership roles would occur.

Study 2- Gender Differences in UC Higher Educational Leadership Compensation: Are women leaders at UC institutions compensated the same as their male colleagues in a comparable position? It was hypothesized that women leaders at the University of California (UC) institutions were compensated less than their male colleagues in the same position.

Study 3- Gender Differences in Early Career and Non-early Career Professionals: Is there a significant difference in the proportion of early-career professionals versus non-early career professionals between men and women in higher educational leadership? It was hypothesized that women who recently began their career hold a majority of higher education leadership positions when compared to men in early-career professions.

\section{METHODS AND PROCEDURES}

The study utilized an ex-post facto design where publicly available data were analyzed to identify gender differences in representation, compensation, and career trajectories of leaders in the UC system. ${ }^{12}$ The method for the study applied the UC Annual Payroll Compensation public database to collect and analyze data from a sample size of 424 chancellors, vice chancellors, provosts, associate, assistant and divisional deans. Participants were from ten public four-year institutions within the UC system. These positions were selected from organizational charts found on the University of California Office of the President website which is maintained by the President's Executive Office. The website offered a link to each school's organizational chart. The authors included the positions mentioned above as they were found in all ten universities and listed based on role importance and size. The role of the president was omitted because one woman fulfills this role, therefore making dichotomous gender comparisons impossible. After gathering data from the public database, the data were split among the researchers, who looked for missing variable information in online school biography statements. Data was compiled, coded, and analyzed using SPSS. Each study had no significant missing data, however, the total sample sizes of all three studies vary slightly. 


\section{Gender Representation in UC Higher Educational Leadership}

A quantitative study with one dichotomous variable, gender, and one nominal variable with ten levels (chancellors, executive vice chancellor and provost, vice chancellor, assistant vice chancellor, college provost, vice provost, dean, associate dean, assistant dean, Senior VP and Senior VC) was done.

\section{Gender Differences in UC Higher Educational Leadership Compensation}

A 2x7 design was used in this quantitative study. The two independent variables examined were gender (men and women) and leadership position (chancellor, vice chancellor, divisional dean, vice provost, associate dean, assistance vice chancellor, and assistant dean). One hundred and eighty-two women respondents $(M=\$ 232,692.82, S D=\$ 124,271.48)$ and 233 men respondents $(M=\$ 277,656, S D=\$ 154,805.87)$ comprised the sample. Please see Figure 1 for a graph of the average salaries by gender in higher educational leadership positions within the UC system.

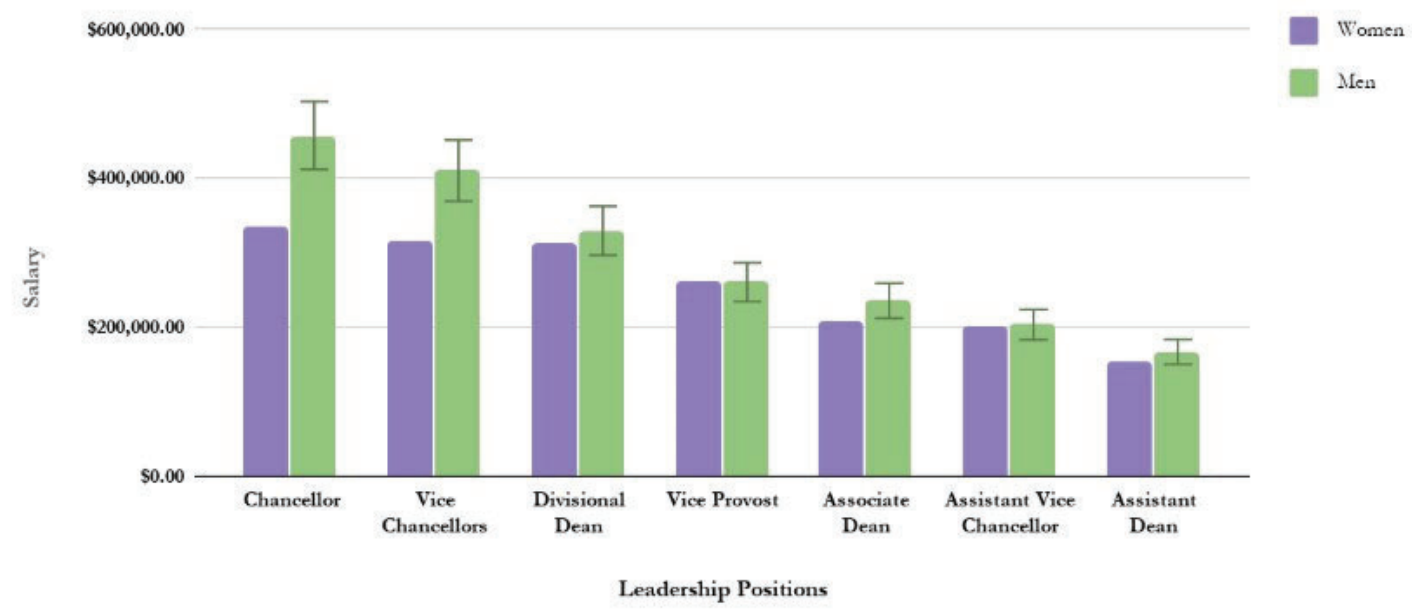

Figure 1. The graph above depicts average salaries by gender in higher education leadership: UC System

\section{Gender Differences in Early Career and Non-early Career Professionals}

This study followed a quantitative design with two dichotomous variables: gender and years since terminal degree. Terminal degree year determined whether a participant was an early career or non-early career professional. The year 2007 was set as the cut-off for consideration as an early career professional, requiring professionals in the sample to have 10 years or less since their terminal degree. ${ }^{13}$ Participants who received their terminal degree before 2007 were considered non-early career professionals. A total of 330 participants were used in this study. There were 194 men and 136 women in this study, where 307 were non-early career professionals and 23 were early career professionals. See Figure 2 for additional demographic details.

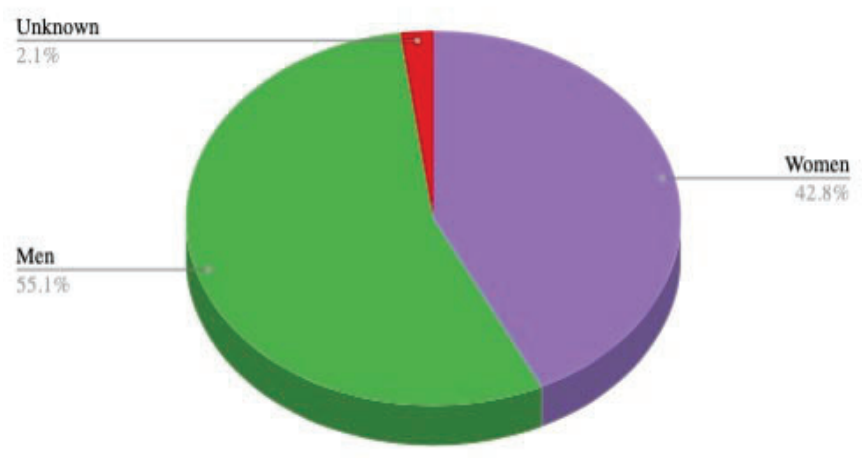

Figure 2. Pie chart of women and men participants 


\section{RESULTS}

Gender Representation in UC Higher Educational Leadership

To summarize the data, a frequency analysis was performed. This resulted in 181 women and 233 men for a total of 414 participants. For the frequency of how many men and women were in each corresponding leadership position, refer to Figure 3. A chi-squared analysis was performed to examine the relationship between gender and leadership position. Analyses revealed there was a statistically significant difference between the representation of men and women in higher education leadership roles, chi-squared $(9, N=414, \mathrm{p}=.002)$ suggesting that men are frequently more represented in these positions than women are. A phi coefficient was calculated to assess the strength of this relationship: phi $=.253$. This corresponds to a medium-size effect. The analyses resulted in rejecting the null hypothesis.

\section{Gender Differences in UC Higher Educational Leadership Compensation}

A two-way ANOVA was used to compare mean salaries of men and women in the same position. The simple main effect of gender on salary was statistically significant $(\mathrm{F}(1,412)=6.839, \mathrm{p}=.009)$. The main effect of leadership title on salary was also statistically significant, $(\mathrm{F}(7,412)=14.921, \mathrm{p}=.000)$ and these null hypotheses were rejected. The interaction between the effect of both gender and leadership title on salary was not statistically significant, $(F(7,412)=.91, \mathrm{p}=.503)$, but a partial eta-squared statistic did indicate a small effect size (partial eta-squared=0.018). In a power analysis, the interaction had a power less than .80 , which suggested that the sample size was too small to detect real differences if they existed. ${ }^{14}$ According to the data, out of the seven ranks, six of them had mean differences where men earned more. For example, women chancellors $(M=\$ 336,774.50$, $S D=\$ 103,457)$ made less than chancellors who were men $(M=\$ 457,761.00, S D=\$ 177,828.73)$, while women divisional deans $(M=\$ 314,377.04, S D=\$ 155,239.90)$ on average were compensated $\$ 15,279$ less than division deans who were men $(M=$ $\$ 329,656.92, S D=\$ 126,373.58)$. Please see Figure 1 for additional gender wage disparities.

\section{Gender Differences in Early Career and Non-Early Career Professionals}

A chi-square analysis was used to see if there was a significant relationship in the frequencies within gender and early versus nonearly career professionals. There was a significant relationship between early career professionals and non- early career

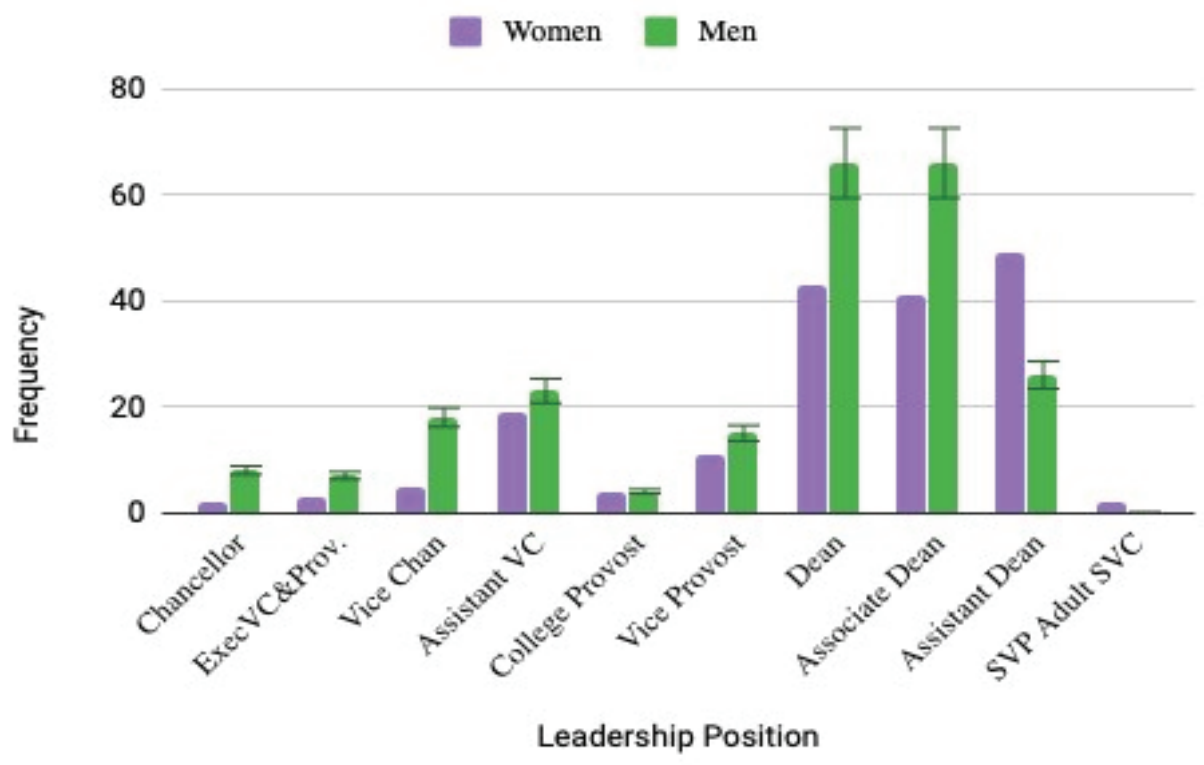

Figure 3. Frequency of men and women in each position

professionals, chi squared $(1, N=330)=272.7, \mathrm{p}=.000$, phi $=0.90$, therefore rejecting the null hypothesis, with a large effect size. There was also a significant relationship within gender, chi squared $(1, N=415)=6.27, \mathrm{p}=.012$, therefore rejecting the null hypothesis, with a small effect size. However, there was not a significant difference in frequency when these two variables were combined, chi squared $(2, N=330)=2.39, \mathrm{p}=.122$, phi $=.085$, showing a small effect size. This suggests that while there are significant differences in the frequency of gender and career level, there is not one for men and women at the nonearly career level nor between men and women at the early career level. There are slightly more women at the early career level and more men at the non-early career level. Although this is non-significant, the percentage of women being hired at the early career level is higher than at the non-early career level. Please see Figure 4 for the frequency of career levels and gender. 


\section{DISCUSSION}

Together these three studies suggest that gender disparities still exist in the leadership of the UC system. These differences under investigation exist in California, the state that holds the narrowest gender wage gap. ${ }^{11}$

\section{Gender Representation in UC Higher Educational Leadership}

There are a wide variety of factors that contribute to the lack of gender parity within higher educational leadership. For starters, researchers argued that the structure of higher education institutions often reflect gendered values and trends. ${ }^{15}$ It was also found that many women fail to progress through the academic hierarchy when compared to their male counterparts over time. Analysis of women in higher education leadership roles in Australia demonstrate a higher proportion of women in lower ranks, estimating about only $11 \%$ of women in the country being full professors. ${ }^{16}$ This suggests that women want to be in higher education leadership roles, however they face hurdles when advancing in their careers. Additionally, researchers found that the women they interviewed felt they had to navigate a "masculine context" in which their university leadership operated and therefore adapt to overcome obstacles to excel and fit into leadership positions. ${ }^{7}$ This means that for women leaders to succeed in university administration, they often have to conform to the masculine norms already in place.

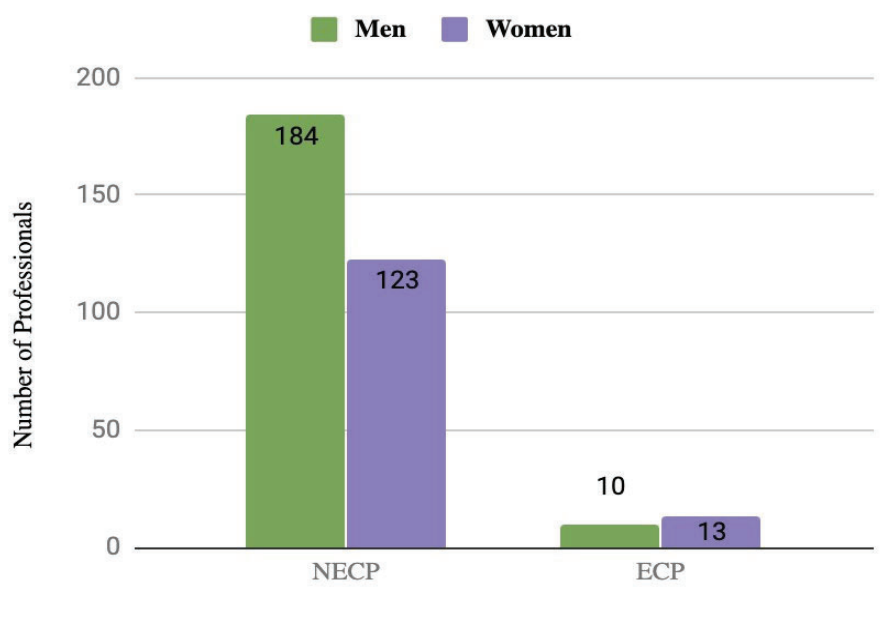

Non-Early Career (NECP) vs. Early Career Professionals (ECP)

Figure 4. Distributions of Non-Early and Early Career Professionals by Gender

Along with patriarchal and structural conditions, another common obstacle identified was a lack of women mentors during women's ascension to higher leadership positions. ${ }^{17}$ In a study analyzing the gender differences in perceptions of STEM workplace climates, it was found that $18 \%$ of the total participants indicated having a mentor, while $58 \%$ of those were men and $38 \%$ were women. ${ }^{18}$ Without access to representative mentorship, women in higher education administration are often left to navigate through the academic hierarchy on their own.

Although progress has been made, obstacles still exist for women leaders in university administration today. For example, gender impacts the perception of leadership abilities, professional relationships, and personal relationships in women college presidents. ${ }^{19}$ The results of this study indicated that $61 \%$ of participants felt that their gender contributed to feelings of isolation within the institutional setting and $53 \%$ of participants agreed that perceptions of gender affected their ability to influence or "restructure" the institution overall. This shows that issues arise due to gender even for those women who can make it to the top of their field. Additionally, personal obstacles have been found to affect women more than men. A study done by the Department of Political Science at the University of Colorado argued that women in managerial positions have higher levels of work-family conflict that can be associated with health issues, problems with drinking, and high stress levels. ${ }^{20}$ The results from this four-year study determined that women leaders in managerial positions experienced more work-family conflict and health risks as compared to men in the same positions.

The results from the current study are in alignment with several other research studies on the gender gap in professional leadership roles. Another recent study aimed at finding the reasons behind the gender gap created three models to explain women's under representation. ${ }^{21}$ The individual, or meritocracy model, explained that women were the cause for their under representation; that the university's perspective was that women were not assertive enough or did not possess enough desire for higher positions, causing the gender gap. The second model is the organizational or discrimination model, which detailed that 
the educational system and its practices that discriminated against women in higher positions were to blame for the under representation. Lastly, the "women's place or social model" detailed society's norms and the socialization patterns of women and men; thus, seeing more men hold higher roles than women.

An additional study identified social constructs as barriers to women in higher education leadership. The author argued that the representation of women at senior academic levels have not yet achieved the same numbers as male colleagues in these positions despite the existence of various equity programs in universities. ${ }^{22}$ A solution for this issue is that academic women need to challenge these hierarchical relations. This could be done by addressing the societal opposition between work and family, passing the challenge on to the next generation, and exposing gendered career structures.

Gender inequity is a prevalent issue in higher education administration today. Although some progress has been made, much more needs to be achieved to level out the playing field between men and women in university administration leadership. This research can be used to help public and private colleges and institutions develop policies to combat this issue and help address the systemic barriers that exist for women looking to advance in higher education careers.

\section{Gender Differences in UC Higher Educational Leadership Compensation}

These findings are consistent with recent research on California's compensation of women and men across industries. In 2017 there was an average wage gap between employed men and women in California of over $\$ 12,000$; the results of our study indicate an average disparity of over $\$ 50,000$ where men are the higher earners, supporting the argument that income is largely dependent on industry and sample size. ${ }^{23}$ While some argue that pay discrimination between genders is decreasing, it has been found that education as a career field in the public sector allows for greater "bureaucratic regulation" or systematic and formalized criterion for compensation than the private sector. ${ }^{24}$ This could also be due to a perceived superior level of transparency that public education models as an employer, where private sectors report compensation less often.

Compensation as a tool for a better quality of life can be used to assess the lasting effects of the gender wage gap. According to the National Institute of Retirement Security, women are $80 \%$ more likely than men to live in poverty at the age of 65 and three times more likely once they reach $75 .{ }^{25}$ In careers where women earn less than men, a cycle of saving less while living longer persists. It's important to see the pattern of wage distribution over the lifespan and between genders because of its effects on wellbeing and ability to reach retirement. Women over the age of thirty report the highest difference in salary from men over thirty, with absence from the workforce due to childbearing and less years of experience as two contributing factors. ${ }^{23}$ Theoretically, all people should earn more as they advance in their careers, however, there is evidence to support that women's salaries often stagnate in competitive environments while men's continue to increase. ${ }^{26,27}$ The effects of salary on women in higher education leadership reinforce economic and cultural insecurities about money and financial independence.

There are consequences of a gender wage gap that reach beyond the seven administrative positions analyzed in this study. Inequities in compensation between men and women in leadership positions are also shown to have adverse effects on the salaries and experiences of women in lower level teaching positions as well. ${ }^{28}$ While location and academic discipline were not reviewed in this study, in support of the hypothesis, some factors that influence salary include years of experience and administrative positions. The data indicated that women occupied both the highest, the president, and the least compensated administrative position, assistant dean, in the UC system. As a result, the gender wage gap was identified as a structural element that impacted all leadership levels differently. This public data can be used as a key source for candidates of leadership positions in higher education to participate in salary negotiations and continue to be informed individuals. Similarly in other industries like politics and public service, where women face unfair biases in campaigns and distorted media coverage, scientific approaches to the disparity could lead to changing perceptions of women leaders. ${ }^{29}$ The implication of this research supports further research into various factors that impact the compensation of women leaders in academia across the country and to women leaders beyond education.

Hiring professionals and candidates for leadership positions could benefit from further development of theories around gender equity in the workplace. One limitation to this study was that there were more men $(56 \%)$ than women $(44 \%)$ in the sample size, which contributed to the increased mean representing men's salaries in the UC system. 


\section{Gender Differences in Early Career and Non-Early Career Professionals}

The results suggest that more early career professional women were hired than early career professional men, although this difference was not statistically significant. While this study did not test the effectiveness of programs structured to increase faculty equity, there are several possible factors that explain why more women are present among early career professionals than men. ${ }^{30}$ One possible factor, is the President's Postdoctoral Fellowship Program which was initiated by the UC president to help women get into tenure-track positions at any of the general UC campuses.

The cornerstone of the President's Postdoctoral Fellowship Program is the accessibility to mentorship it provides to participants. Having a mentor gives women a push in climbing up the academic ladder since having an individual with power who can vouch for a rising academic professional can make a difference. ${ }^{25} \mathrm{~A}$ mentor can direct their mentees to leadership development opportunities and other professionals in the field. Studies show that women leaders are viewed as more authentic by women peers. ${ }^{31}$ This suggests that in some cases a woman having a mentor of the same sex can be more beneficial than having a mentor of the opposite sex. As part of the President's Postdoctoral Fellowship Program, UC President Janet Napolitano gave five million dollars to continue a salary hiring incentive and to begin an incentive to hire current and former UC President's and Chancellor's postdoctoral fellows. The office of the UC President released statements on the program stating that sixteen out of fifty-eight fellows have been hired in the same campus in which they were fellows. ${ }^{10}$ This initiative shows that programs can help reach faculty gender-equity, by giving women academic professionals somewhere to start.

Leadership development programs in partnership with women's centers can help women build a professional network and selfconfidence. ${ }^{9}$ Participants stated that the program gave them a space to develop their identities as professionals and normalize concerns about the workforce. Programs directed toward developing leadership skills in women are essential because they provide a shared space to talk about the experience's women face as potential academic professionals.

\section{CONCLUSIONS}

Limitations of this study include missing information concerning age, ethnicity, and academic discipline that were examined. It is essential to acknowledge that despite the progress that has been made in addressing the gender gap that exists in the workplace, there are still many fields in which men disproportionately outnumber women. This study only considers whether individuals are a non-early career or early career, versus looking at their entire progression up the administrative ladder, due to the data being from a single year. Future studies should follow professionals throughout their academic career to clarify the difference, if any, of the patterns of advancement and the amount of time it takes to advance between the genders.

The study also used the year in which individuals attained their terminal degree rather than the year they were hired. Future studies should address this limitation and look at gender disparity in hires among different departments. Additionally, the hiring practices different departments within the UC System use should also be taken into consideration.

The purpose for this study was to gain a better understanding of gender representation, compensation, and career progression in higher education leadership positions within 10 schools in the UC system. This study contributed to the existing research on women in higher educational leadership and provided an understanding of the gender gap within one of the largest higher education systems in the state of California. Logical extensions of this research could include investigating other higher education systems in other states; particularly in states with wider gender wage gaps than California. Results from this study suggest that gender inequity in higher education leadership is still a pervasive issue.

\section{REFERENCES}

1. Kalev, A., and Deutsch, G. (2018) Gender inequality and workplace organizations: Understanding reproduction and change, in Handbook of Sociology and Gender, (Risman B., Froyum C., and Scarborough W. Eds.) 2nd ed., 257-269. Springer Cham, New York. https:// doi.org/10.1007/978-3-319-763330_19

2. Isaacs, A. J. (2014) Gender differences in resilience of academic deans, Journal of Research in Education, 24(1), 112-119. https:/ / files.eric.ed.gov/ fulltext/EJ1098305.pdf(accessed Feb 2019)

3. U.S. Census Bureau, American community survey 5 year-estimate, bttps://datausa.io/profile/geo/california/(accessed Feb 2019)

4. Bureau of Labor Statistics, Labor Force Statistics from the Current Population Survey, https:// www.bls.gov/cps/demographics.htm (accessed Jan 2019)

5. American Council on Education's Center for Policy Research and Strategy, Women Presidents Profile, bttps:/ / www.aceacps.org/women-presidents/ (accessed Mar 2019)

6. Johnson, K. A., Warr, D. J., Hegarty, K., and Guillemin, M. (2015) Small wins: An initiative to promote gender equity in higher education, Journal of Higher Education and Management 37, 689-701. https:/ / doi.org/10.1080/1360080X.2015.1102820 
7. Burkinshaw, P., and White, K. (2017) Fixing the women or fixing universities: Women in higher education leadership, Administrative Sciences, 7(30), 1-14. https:/ / EconPapers.repec.org/RePEc:gam:jadmsc:v:7:y:2017:i:3:p:30-:d:109122 (accessed Feb 2019)

8. Lepkowski, C. (2009) Gender and the career aspirations, professional assets, and personal variables of higher education administrators, Advancing Women in Leadership Journal, 27(6), 1-15. https:/ / doi.org/10.18738/ awl.v29i0.284

9. Bonebright, D. A., Cottledge, A. D., and Lonnquist, P. (2012) Developing women leaders on campus: A human resourceswomen's center partnership at the University of Minnesota, Advances in Developing Human Resources, 14(1), 79-95. bttps:/ / doi.org/10.1177/1523422311429733

10. University of California, About President's Postdoctoral Fellowship Program, https://pppp.ucop.edu/info/about-pppp/index.html (accessed Feb 2019)

11. American Association of University Women (AAUW), The gender pay gap by state: An interactive map, bttps:/ / wmw.aauw.org/ resource/gender-pay-gap-by-state-and-congressional-district/ (accessed Jan 2019)

12. UC Office of the President, University of California employee pay, https:// ucannualwage.ucop.edu/wage/ (accessed Jan 2019)

13. American Geophysical Union, Career stages and other terms definitions, https:// honors.agu.org/career-stages-andother-termsdefinitions/(accessed Feb 2019)

14. Cohen, J. (1992) Statistical Power Analysis, Current Directions in Psychological Science, 1(3), 98-101. http:/ / www.jstor.org/stable/ 20182143 (accessed Feb 2019)

15. Maphalala, M., and C. Mpofu, N. (2017) Are we there yet? A literature study of the challenges of women academics in institutions of higher education, Gender Behavior, 9245-9253.

https:/ / www.researchgate.net/publication/318455987_Are_we_there_yet_A_literature_study_of_the_challenges_of_women_academic_in_in stitutions_of_higher_education

16. White, K. (2004) The leaking pipeline: Women postgraduate and early career researchers in Australia, Tertiary Education and Management, 10(3), 227-241, https:/ / doi.org/10.1080/13583883.2004.9967129

17. Ballenger, J., and Stephen, F. (2010) Women's access to higher education leadership: Cultural and structural barriers, Forum on Public Policy Online: A Journal of the Oxford Round Table 5, 1-20. https://files.eric.ed.gov/fulltext/EJ913023.pdf (accessed Mar 2019)

18. Riffle, R., Schneider, T., Hillard, A., Polander, E., Jackson, S., Des Autels, P., and Wheatly, M. (2013) A mixed methods study of gender, STEM department climate, and workplace outcomes, Journal of Women and Minorities in Science and Engineering, 19(3), 227-243. https:/ / doi.org/10.1615/JWomenMinorScienEng.2013005743

19. Caton, M. T. (2007) Common trends in U.S. women college president issues, Forum on Public Policy 3, 1-26. https:/ / www.semanticscholar.org/paper/Common-Trends-in-U.S.-Women-College-PresidentCaton/7b3933b2b66f5692b6080973edbd40091c74b8db\#citing-papers (accessed Feb 2019)

20. Apperson, M., Schmidt, H., and Moore, S., Grunberg, L. (2002) Women managers and the experience of work-family conflict, American Journal of Undergraduate Research, 1(3), 9-16. https:/ / doi.org/10.33697/ ajur.2002.020

21. Growe, R., and Montgomery P. (1999) Women and the leadership paradigm: Bridging the gender gap, National Forum Journal 17, 1-21. https:// www.researchgate.net/publication/242783132_Women_and_the_leadership_paradigm_bridging_the_gender_gap (accessed Feb 2019)

22. White, K. (2003) Women and leadership in higher education in Australia, Tertiary Education and Management, 9(1), 45-60. https:// doi.org/10.1080/13583883.2003.9967092

23. Archer, E. (2018) A closer look: Establishing the gender pay gap, The Report on the Status of Women and Girls in California, 1617, https:// wnw.msmu.edu/media/website/content-assets/msmuedu/bome/academics/financialaid/documents/StatusOfWomenCA2018_WEBFIN AL[5].pdf (accessed Feb 2019)

24. Mandel, H., and Semyonov, M. (2014) Gender pay gap and employment sector: Sources of earnings disparities in the United States 1970-2010, Demography, 51(5), 1597-1618. https://doi.org/10.1007/s13524-014-0320-y

25. Brown, T. M. (2005) Mentorship and the female college president, Sex Roles, 52(9), 659-666. bttps:// doi.org/10.1007/s11199-005-3733-7

26. Gneezy, U., and Rustichini, A. (2004) Gender and Competition at a Young Age, American Economic Review, 94 (2), $377-381$. bttps:/ / doi.org/10.1257/0002828041301821

27. Niederle, M., Vesterlund, L. (2008) Gender differences in competition, Negotiation Journal, 24(4), 447-463. https:// doi.org/10.3386/w13727

28. Cohen, P. N., and Huffman, M. L. (2007) Working for the woman? Female managers and the gender wage gap, American Sociological Review, 72(5), 681-704. https:// doi.org/10.1177/000312240707200502

29. Bjerre, K. (2018) The role of gender stereotypes in gubernatorial campaign coverage. American Journal of Undergraduate Research, 15(1), 55-69. https:/ / doi.org/10.33697/ ajur.2018.012 
30. UC Office of the President, UC launches major push to increase faculty diversity. https:// wmw.universityofcalifornia.edu/pressroom/uc-launches-major-push-increase-faculty-diversity (accessed Jan 2019)

31. Tibbs, S., Green, M. T., Gergen, E., and Montoya, J. A. (2016) If you are like me, I think you are more authentic: An analysis of the interaction of follower and leader gender, Administrative Issues Journal: Connecting Education, Practice, and Research, 6(1), 118-133. https:/ / eric.ed.gov/ ?id=EJ1104359

\section{ABOUT THE AUTHORS}

Carla Cañas graduated from Mount Saint Mary’s University, Los Angeles in May 2019 with her B.A. in Psychology. She is currently working as a research assistant at the Keck School of Medicine of USC in a preventive study for Alzheimer's disease. She wishes to pursue her Ph.D. in neuropsychology and become a University professor and researcher in the future.

Caitlyn Keeve completed this manuscript as a junior at Mount Saint Mary's University, Los Angeles. She will graduate with a B.A. in Psychology with an emphasis in research Fall 2019. After graduation, she plans to pursue a Ph.D. in Social Psychology. Her goal is to become a published author and a University professor in the future.

Carmen Ramos completed this manuscript as a junior at Mount Saint Mary's University. She will graduate with a B.A. in Psychology in the spring of 2020. Her future education plans include obtaining a graduate degree in industrial/organizational psychology.

Jocelyn Rivera graduated from Mount Saint Mary's University in December 2018 with her B.A. in Psychology. She is currently working as a Registered Behavior Technician to help children with autism and other developmental delays. She plans to obtain a graduate degree in Behavior Analysis and become a Board-Certified Behavior Analyst.

Michelle L. Samuel is an Assistant Professor of Psychology at Mount Saint Mary's University. She has an M.A. in General Experimental Psychology and is pursuing a Ph.D. in Higher Education Administration. She will investigate gender differences in academic leadership for her dissertation.

\section{PRESS SUMMARY}

This research investigates the representation, career progression, and compensation disparities of women in higher education leadership when compared to men. Significant differences in gender equity among deans, chancellors, and provosts in the University of California system were found in this analysis. With more men represented at several levels of educational leadership, a gender wage gap also revealed that men earned more money than women in the same administrative position. When comparing early-career women to non-early career, the percentage of women being hired at the early-career level is higher than later in their careers. This study contributes to the existing research on women in higher education leadership and provides an understanding of the gender gap within one of the largest higher education systems in the state of California. 